\title{
Neutral Fetal Attitude
}

National Cancer Institute

\section{Source}

National Cancer Institute. Neutral Fetal Attitude. NCI Thesaurus. Code C92835.

A position of the fetus during the labor and delivery process where the fetal chin is mildly flexed but with a forward facing head. 